\title{
Teoria da agência e terceirização: uma proposta de modelo teórico para contratação e gerenciamento de serviços de tecnologia da informação
}

\section{Ronalty Oliveira Rocha}

Mestrando em Administração pela Universidade Federal de Sergipe

ronaltyrocha@gmail.com

\section{Maria Conceição Melo Silva Luft}

Doutorado em Administração pela Universidade Federal de Pernambuco.Docente do Programa de Pós -Graduação em Administração- PROPADM/UFS e do Programa de Mestrado Profissional em Administração -(PROFIAP).

ceica@infonet.com.br

\section{Maria Elena Leon Olave}

Doutora em Engenharia de Produção pela Universidade de São Paulo. Docente do Programa de Pós Graduação em Administração- PROPADM/UFS e do Programa de Mestrado Profissional em Administração -(PROFIAP).

mleonolave@gmail.com

\section{Florence Cavalcanti Heber Pedreira De Freita}

Doutorado em Administração pela Universidade Federal da Bahia. Professora adjunta III do departamento de administração na Universidade Federal de Sergipe - Docência na Graduação e Mestrado em Administração.

florenceheber@hotmail.com

\section{Editor Científico: José Edson Lara}

Organização Comitê Científico

Double Blind Review pelo SEER/OJS

Recebido em 07.02.2018

Aprovado em 28.04.2018 


\title{
Resumo
}

Nem todas as organizações estão técnica e gerencialmente aptas a extrair potencialidades e alcançar reais benefícios pelo uso da tecnologia da informação (TI), principalmente no tocante ao gerenciamento de serviços de tecnologia da informação. Nesse contexto, ganha expressividade os relacionamentos obtidos com a terceirização da TI, todavia esses relacionamentos oferecem riscos e dificuldades que podem ser melhor compreendidos pelo uso da teoria da agência. Assim, este estudo, por meio de um ensaio teórico, tem como objetivo propor ações capazes de minorar os problemas concebidos em relacionamentos de terceirização de tecnologia da informação, principalmente aqueles relativos ao problema de agência. Utilizou-se a teoria da agência para propor um modelo teórico com mecanismos de mitigação de riscos relacionados a conflitos de interesses, assimetria de informações, custos de agência e práticas de oportunismo em processos de contratação e gerenciamento de serviços terceirizados de TI.

Palavras-chave: Terceirização de TI, Teoria da agência, Mitigação de riscos.

\section{Theory of agency and outsourcing: a proposal of a theoretical model for hiring and managing information technology services}

\begin{abstract}
Not all organizations are technically and managerially apt to extract potentialities and achieve real benefits through the use of information technology (IT), especially in the management of information technology services. In this context, the relationships obtained with the outsourcing of IT gain expressivity, but these relationships present risks and difficulties that can be better understood through the use of agency theory. Thus, this study, through a theoretical essay, aims to propose actions capable of alleviating the problems conceived in outsourcing relationships of information technology, especially those related to the problem of agency. The agency theory was used to propose a theoretical model with risk mitigation mechanisms related to conflicts of interests, information asymmetry, agency costs and opportunistic practices in hiring and outsourcing IT service management processes.
\end{abstract}

Keywords: IT outsourcing, agency theory, Risk Mitigation. 
Teoría de la agencia y tercerización: una propuesta de modelo teórico para la contratación y gestión de servicios de tecnología de la información

\section{Resumen}

No todas las organizaciones están técnica y gerencialmente aptas para extraer potenciales y alcanzar verdaderos beneficios por el uso de la tecnología de la información (TI), principalmente en lo que se refiere a la gestión de servicios de tecnología de la información. La tercerización de la TI ofrecen riesgos y dificultades que pueden ser mejor comprendidos por el uso de la teoría de la agencia. Así, este estudio, a través de un ensayo teórico, tiene como objetivo proponer acciones capaces de mitigar los problemas concebidos en relaciones de tercerización de tecnología de la información, principalmente aquellos relativos al problema de agencia. Se utilizó la teoría de la agencia para proponer un modelo teórico con mecanismos de mitigación de riesgos relacionados con conflictos de intereses, asimetría de informaciones, costos de agencia y prácticas de oportunismo en procesos de contratación y gestión de servicios tercerizados de TI.

Palabras clave: Tercerización de TI, Teoría de la agencia, Mitigación de riesgos.

\section{Introdução}

Para garantir melhor desempenho, e um nível mínimo de qualidade para o atendimento de clientes e funcionários, a área interna de tecnologia nas organizações necessita de metodologias e ferramentas que representam altos custos de aquisição e manutenção (Foina \& Lima, 2014). Nesse contexto, desponta a terceirização de tecnologia da informação como uma alternativa às organizações que querem melhorar sua performance de negócios sem incorrer em grandes custos. A terceirização de TI começou a notabilizar-se no final dos anos de 1980 com a crescente tendência das organizações em transferir seus sistemas de informação para provedores externos. Hoje, essa prática tem se tornado comum nos mais variados ramos de negócios pelo mundo e vem se consolidando como uma estratégia organizacional capaz de melhorar a produtividade e eficiência organizacional, e consequentemente agregar valor às organizações participantes (Gomes, 2014).

No Brasil, segundo a associação brasileira de empresas de software (Abes, 2016) as empresas do setor de TI movimentaram R \$ 59,9 bilhões de reais e geraram 120.000 empregos 
diretos em 2015. Destaca-se também que em 2017, conforme o relatório Global Services Location Index da consultoria A.T Kearney, o Brasil alcançou a quinta posição mundial no ranking de países prestadores de serviços de terceirização de TI e segundo projeções da consultoria IDC Brasil (Gens, SVP \&Chief Analyst, 2017), o mercado de TI, em 2018, terá aumento de 5,8\% em investimentos em relação ao ano de 2017.

Nessa direção, inicialmente, apresenta-se a terceirização de tecnologia da informação como o relacionamento contratual, mediante recompensas financeiras, pelo qual uma organização contratante transfere a outra (fornecedor ou contratado) a responsabilidade de operar e gerir serviços e/ou funções internas de TI com o objetivo de alcançar vantagens estratégicas, benefícios de custos e focar em suas competências organizacionais primordiais (Samantra, Datta, \& Mahapatra, 2014).

A teoria da agência, por sua vez, tem como base entender como se constituem e são gerenciados os mais diversos relacionamentos (relação de agência) entre atores organizacionais. Essa perspectiva teórica trata das relações contratuais entre diversos tipos de principal e agente (proprietários e acionistas; administradores e gestores; clientes e fornecedores), assim como dos mecanismos de incentivo e gerenciamento pertinentes a tais relações (Moraes, 2015). A relação de agência é explicada pela metáfora de um contrato sob o qual a organização contratante motiva a organização contratada para desempenhar algum serviço que envolva delegação de tomada de decisão. Além disso, a teoria da agência coloca em evidência dificuldades relacionadas a conflitos de interesses, assimetria de informações e custos de monitoramento nos relacionamentos organizacionais (Jensen \& Meckling, 1976). Tais aspectos são também percebidos como dificuldades nos relacionamentos de terceirização. Por este motivo a teoria da agência é uma das mais proeminentes teorias que têm sido usadas para analisar contratos de terceirização, e propor mecanismos para mitigação de riscos e resolução de problemas concebidos em relacionamentos terceirizados (Gorla \& Somers, 2014).

Estudos sobre a temática terceirização de TI são diversos. Merece destaque também o trabalho de Gomes (2014), que semelhante a esse estudo associou as abordagens da teoria da agência e da terceirização de TI, ao identificar a influência conjunta da teoria da agência e da teoria de desenvolvimento de grupos nos resultados de projetos de terceirização de TI. Contudo, no trabalho de Gomes (2014), alguns pressupostos da teoria da agência não foram discutidos na contratação de serviços de TI. 
Com base nisso, este estudo objetiva propor ações capazes de minorar os problemas concebidos em relacionamentos de terceirização de tecnologia da informação, principalmente aqueles relacionados ao problema de agência. Para tanto, adotou-se uma abordagem ensaística. Segundo Meneghetti (2011) o ensaio teórico provoca reflexões sobre o tema estudado, assim como promove a construção de novos conhecimentos e percepções.

Assim, o artigo que ora se apresenta busca contribuir com a discussão sobre a teoria da agência e a terceirização de TI e se diferencia por analisar, e propor um modelo teórico, sobre como cada um dos pressupostos de assimetria de informações, conflitos de interesses e custos de agência podem ser minimizados em relacionamentos de terceirização de tecnologia da informação.

\section{Teoria da agência}

Proposta por Jensen e Meckling (1976) a teoria da agência aborda o conflito de interesses e assimetria de informações dentro das organizações e no relacionamento entre os mais diferentes atores organizacionais. Heracleous e Lan (2012), em definição mais detalhada, propõem a teoria da agência como o conjunto de conceitos compreendidos e analisados nos relacionamentos organizacionais em que há alguém - o principal - pede a outra pessoa - o agente - para gerenciar seus investimentos e/ou bens, mediante compensação financeira. Esses autores ainda destacam que a teoria da agência estuda os problemas e soluções ligados a delegação de tarefas sob assimetria de informação, conflito de interesses, risco moral e oportunismo entre duas ou mais partes.

Inicialmente, é de ressaltar que existem duas correntes principais em teoria da agência: a positivista e a principal-agente. A corrente positivista, que tem como origem o trabalho de Jensen e Meckling (1976), enfatiza contextos onde o principal e o agente possuem objetivos divergentes e explica os mecanismos de governança formulados para inibir o comportamento autocentrado do agente. A corrente principal-agente, por sua vez, empenha-se no estudo geral da teoria da agencia e sua aplicação em diversos tipos de relacionamentos como empregadorempregado, advogado-cliente, cliente-fornecedor, dentre outros (Gomes, 2014; Bendickson, Muldoon, \& Liguori, 2016).

Na perspectiva positivista, Jensen e Meckling (1976) definem uma relação de agência como um contrato no qual uma ou mais pessoas (principal) delega a outra (agente) a obrigação de realizar algum serviço que envolva a tomada de decisão. Segundo Eisenhardt 
(1989) o foco da teoria da agência está nas relações de agência: duas partes têm uma relação de agência quando cooperam em uma associação em que o principal delega decisões e/ou trabalho para o agente agir em seu nome. Na relação de agência o agente tem o compromisso de realizar alguma atividade para o principal, e o principal tem o compromisso de remunerar o agente por isso (Rocha, Pereira, Bezerra, \& Nascimento, 2012). Esse entendimento é corroborado por Klann, Gomes, Greuel e Bezerra (2014) que expõe a teoria da agência como o estudo sobre como um indivíduo ou organização - o principal - estabelece um sistema de compensação - contrato - que instiga outro indivíduo (o agente) a agir de acordo com o interesse do principal.

Mitchell e Meachem (2011) revelam que o foco da teoria da agencia deriva de pressupostos de que o agente irá se comportar de forma oportunista, especialmente se seus interesses forem contrários ao do principal. Assim, a questão mais relevante da teoria da agência é entender como se dá o relacionamento entre contratantes e contratados e como são gerenciados os problemas que daí surgem (Machado, Garcia, Oliveira \& Marques, 2015).

Ademais, a melhor compreensão da proposta conceitual da teoria da agencia contempla o entendimento dos pressupostos de conflitos de interesse, assimetria de informações e custos de agência (Jensen \& Meckling, 1976).

\subsection{Conflito de interesses e assimetria de informações}

Braga, Horbucz e Cherobim (2015) exploram que em relacionamentos de agência os conflitos de interesse podem surgir quando há discrepância de objetivos entre as duas partes, isso geralmente ocorre quando o agente busca seus interesses próprios, como satisfação pessoal e maximização de benefícios, em agravo aos objetivos do principal.

Nessa mesma perspectiva, Jensen e Meckling (1994) explicam que os conflitos surgem porque o comportamento dos indivíduos está sempre fundamentado em seu próprio conjunto de preferências e objetivos. Moura, Daniel, Gomes e Pereira (2014) detalham que ao buscar seus próprios interesses, o agente pode empreender ações divergentes aos objetivos do principal e é, justamente, tal desentendimento que caracteriza o conflito de interesses e desencadeia situações de oportunismo.

O Tabela 1 expõe alguns esclarecimentos acerca do pressuposto de conflito de interesses nos relacionamentos de agência. 
Tabela1

Conflito de interesses

\begin{tabular}{|l|l|}
\hline Autor & \multicolumn{1}{c|}{ Conflito } \\
\hline $\begin{array}{l}\text { Klann } \text { et al., } \\
(2014)\end{array}$ & $\begin{array}{l}\text { Ocorre quando o agente, que deveria agir no melhor interesse do principal - } \\
\text { causa pela qual é contratado - comporta-se em prol de seu próprio interesse } \\
\text { buscando potencializar sua utilidade pessoal. }\end{array}$ \\
\hline $\begin{array}{l}\text { Braga, Horbucz e } \\
\text { Cherobim (2015) }\end{array}$ & $\begin{array}{l}\text { O principal delega decisões que influenciam seus retornos financeiros a outra } \\
\text { parte - o agente, que nem sempre compactua com os interesses do principal. }\end{array}$ \\
\hline $\begin{array}{l}\text { Linder e Foss } \\
(2015)\end{array}$ & $\begin{array}{l}\text { Emerge quando o principal não possui conhecimentos mais apurados acerca da } \\
\text { atividade delegada, e não consegue, satisfatoriamente, avaliar o desempenho do } \\
\text { agente sobre a mesma. }\end{array}$ \\
\hline
\end{tabular}

Fonte: Elaborado pelos autores (2017)

Os problemas decorrentes dos conflitos de interesses podem ser minimizados de diferentes maneiras, entre as quais: procedimentos de monitoração, restrições contratuais, elaboração periódica de diversos tipos de relatórios, realização de auditorias e criação de um sistema de incentivos que alinhem os interesses das partes divergentes (Jensen \& Meckling, 1976).

Jensen e Meckling (1976) explicam que os conflitos de interesses são causados, na maioria das vezes, pela distribuição assimétrica de informações entre o principal e o agente. A assimetria de informações é a diferença existente, em uma relação contratual, entre o agente e o principal em função de uma parte possuir mais informação do que a outra (Rocha et al., 2012). Isto posto, a assimetria de informações pode ser caracterizada como uma situação na qual uma das partes envolvidas numa transação não possui toda a informação relevante e necessária para averiguar se os termos do contrato são mutuamente aceitáveis e em condições para implementação (Arruda, Madruga, \& Freitas Junior, 2008).

Braga, Horbucz e Cherobim (2015) expõem que o principal pode enfrentar desvantagens quanto à assimetria de informações de duas formas distintas: primeiro quando o agente não revela, integralmente, seus interesses, conhecimentos e potencialidades já no momento da contratação e segundo quando o agente desempenha tarefas, no decorrer do contrato, de modo oportunista, não dedicando esforços para maximizar retornos para o contratante.

É de ressaltar que a existência de conflitos de interesses e assimetria de informações faz com que o principal (contratante) invista maior volume de recursos financeiros para monitorar 
o comportamento do contratado e, consequentemente, obter melhores resultados no relacionamento com o agente (contratado). Esses dispêndios correspondem aos custos de agência, isto é, aos gastos gerados para nivelar os interesses do agente e do principal (Machado, 2012), conforme é explicado na próxima seção.

\subsection{Custos de agência}

Os custos de agência surgem dos esforços do principal para que o agente haja conforme o acordado, isto é, os custos de agência são expressos em mecanismos de controle que visam assegurar que o agente irá trabalhar para satisfazer os interesses do contratante (Machado, 2012). De acordo com Jensen e Meckling (1976), os custos de agência englobam todos os desembolsos do principal para monitorar o agente, tais como despesas de supervisão e custos de elaboração e estruturação de contratos. Kaveski e Cunha (2016) resumem que os custos de agência são desembolsos do principal para que o agente se comporte conforme os objetivos e resultados econômicos da organização na qual está alocado. Esses custos se traduzem em mecanismos para o monitoramento de atividades do agente e/ou o estabelecimento de incentivos para o sincero cumprimento, pelo agente, das clausulas contratuais (Moura et al., 2014).

Klann et al (2014) ainda revelam que para alcançar bons resultados o principal deve oferecer ao agente incentivos de longo prazo e se preocupar com as condições de confiabilidade dessas promessas. Se os funcionários não confiam que o principal vá cumprir suas promessas, incentivos em longo prazo não promoverão efeitos e a organização incorrerá em custos excedentes para monitorar, estimular e controlar o trabalhador. Nesse sentido, Santos, Inácio e Vieira (2015) defendem que a auditoria exerce um papel importante na monitorização dos agentes e, consequentemente, na minimização dos custos de agência. Kaveski e Cunha (2016), por sua vez, explanam que a governança corporativa é uma das melhores e mais eficazes formas de minimizar os custos de agência.

Para Klann et al (2014) o conflito de interesses, assimetria de informações e custos de monitoramento constituem o problema de agência e criam condições para práticas oportunistas (Jensen \& Meckling, 1976). Nesse contexto, Rodrigues (2013) revela que a relação entre o principal e o agente é influenciada por pressupostos comportamentais que envolvem a construção de uma relação pautada por desconfianças e oportunismo. Para esses autores a adoção do comportamento oportunista baseia-se na possibilidade de alguma das 
partes se envolver em transações agindo de forma antiética e conseguindo benefícios próprios em detrimento dos outros participantes.

No tocante ao oportunismo, Linder e Foss (2015) alertam que a teoria da agência pode pintar um quadro demasiado negro da natureza humana assumindo que indivíduos sempre se comportam de forma oportunista. Além disso, os autores esclarecem que é necessário considerar, também, as intenções e práticas oportunistas dos principais, entendendo que estes podem tentar enganar o agente na avaliação de desempenho para reduzir sua recompensa. Práticas oportunistas, conflitos de interesses e custos de agência podem ser identificados em diversos relacionamentos comerciais, inclusive em contratos de terceirização de TI.

\section{Terceirização de tecnologia da informação}

A terceirização é o processo de transferência, total ou parcial, para um ou mais fornecedores, do gerenciamento e manutenção de ativos, serviços, processos de negócios, recursos e atividades produtivas que não representam o negócio essencial da organização, nem se caracterizam como atributos estratégicos da mesma (Cristofoli \& Prado, 2011).

Luciano e Testa (2011) explicam que a expressão terceirização é originária do termo outsourcing em inglês, e descreve uma estratégia que procura fora da empresa (out) a fonte (source) para realização de determinada atividade. Mol (2007) diz que a terceirização se caracteriza como um conjunto de ações, limitadas ou não, por um período de tempo, que transfere atividades organizacionais secundárias para fornecedores externos. Isto é, a terceirização é o processo de criação e gestão de uma relação contratual com um fornecedor externo para o fornecimento de capacidades previamente definidas (Perunovic \& Pedersen, 2007). Assim, Gorla e Somers (2014) resumem a terceirização como um popular mecanismo de governança, através do qual um ou mais serviços são produzidos por um fornecedor externo ao invés de serem concebidos internamente.

A terceirização de TI, por sua vez, originou-se das insatisfações quanto ao custo, qualidade e desempenho das unidades de TI dentro das organizações (Barros, 2008), que passaram a atribuir a terceiros, por meio de arranjos contratuais de longo prazo, a responsabilidade de gerir a totalidade ou parte de sua infraestrutura e operações de TI (Fitoussi \& Gurbaxani, 2012). 
Kim, Lee, Koo e Nam (2013) referem-se a terceirização de TI como o uso de agencias externas para processar, gerenciar ou manter os dados internos e de prestação de serviços relacionados com a informação, incluindo a significativa transferência de ativos, contratos de locação e equipes para um fornecedor externo. Foina e Lima (2014), por seu turno, tratam da terceirização na área de tecnologia como uma prática comum nas empresas, que acabam buscando, em outras organizações, os profissionais e serviços especializados em determinados ramos da informática.

As práticas designadas a terceirização de TI podem incluir tanto atividades, quanto serviços relacionados ao processamento de informações nas organizações. Seguindo essa linha de raciocínio, Gomes (2014), do mesmo modo que Gorla e Somers (2014), afirma que diversas atividades de TI podem ser terceirizadas. Os autores citados chamam atenção para: operação de sistemas, desenvolvimento de aplicações, manutenção de aplicativos, suporte à rede de computadores, gestão de telecomunicações, help desk, suporte ao usuário final e, planejamento e gestão de sistemas. Gonçalves, Polo, Correia e Castelhano Bruno (2014) completam que, além de tais atividades, a terceirização de TI pode incluir a transferência de fatores de produção, tais como pessoas, equipamentos, tecnologias e outros ativos relacionados a TI, como também o direito de decisão sobre estes fatores.

Quanto aos serviços, autores como Vieira, Diógenes, Santos, Oliveira e Quintário (2008) destacam que os serviços mais propícios à terceirização em TI são: manutenção de equipamentos; treinamento em microinformática; programação; manutenção de sistemas; treinamento de usuários; projeto e desenvolvimento de sistemas; microfilmagem; suporte técnico em software; serviço de comunicação de dados; projeto de redes de teleprocessamento; digitação; levantamento e diagnósticos; processamento; definição de metodologias em informática; plano diretor de informática (PDI) e editoração eletrônica.

A literatura revela uma variedade de razões pelas quais as organizações decidem pela terceirização de TI. A tabela 2 apresenta as principais motivações e benefícios identificados, resumidos a partir dos trabalhos de Bergamaschi (2005), Tiwana e Bush (2007), Cristofoli, Prado e Takaoka (2008), Lopes e Silva (2008), Prado (2009), Thouin, Hoffman e Ford (2009), Fitoussi e Gurbaxani (2012) e Gorla e Somers (2014). 
Tabela 2

Motivações e benefícios da terceirização de tecnologia da informação

\begin{tabular}{|c|c|c|}
\hline Motivação & \multicolumn{2}{|c|}{ Benefícios } \\
\hline \multirow[t]{9}{*}{ 1. Redução de custos } & \multicolumn{2}{|c|}{ Redução de custos na aquisição e manutenção de hardware e software } \\
\hline & \multicolumn{2}{|c|}{ Reestruturação do orçamento do setor de TI } \\
\hline & \multicolumn{2}{|l|}{ Preservação do capital da organização } \\
\hline & \multirow[t]{6}{*}{ Redução de custo de mão-de-obra } & $\begin{array}{l}\text { Não exige um quadro permanente de } \\
\text { pessoal. }\end{array}$ \\
\hline & & $\begin{array}{l}\text { Maior aproveitamento do tempo dos } \\
\text { trabalhadores. }\end{array}$ \\
\hline & & Redução das taxas de absenteísmo. \\
\hline & & $\begin{array}{l}\text { Redução de custos com encargos e } \\
\text { benefícios trabalhistas. }\end{array}$ \\
\hline & & Downsizing da organização. \\
\hline & & $\begin{array}{l}\text { Acesso à mão-de-obra especializada } \\
\text { para atividades com demanda } \\
\text { cambiante. }\end{array}$ \\
\hline \multirow[t]{6}{*}{$\begin{array}{l}\text { 2. Focar nas competências } \\
\text { essenciais do negócio }\end{array}$} & \multicolumn{2}{|c|}{$\begin{array}{l}\text { Elimina o ônus da TI, passando ao fornecedor a missão de resolver funções } \\
\text { problemáticas da área de TI. }\end{array}$} \\
\hline & \multicolumn{2}{|l|}{ Facilita fusões e aquisições } \\
\hline & \multicolumn{2}{|c|}{ Melhora o tempo de resposta ao mercado } \\
\hline & \multicolumn{2}{|l|}{ Promove a inovação } \\
\hline & \multicolumn{2}{|c|}{ Melhora o desempenho de processos de negócios } \\
\hline & \multicolumn{2}{|c|}{ Melhora o alinhamento da TI com o negócio } \\
\hline \multirow{3}{*}{$\begin{array}{l}\text { 3. Acesso a } \\
\text { conhecimentos e } \\
\text { tecnologias }\end{array}$} & \multicolumn{2}{|c|}{$\begin{array}{l}\text { Acesso a conhecimento especializado que a empresa não dispõe e deseja } \\
\text { adquirir. }\end{array}$} \\
\hline & \multicolumn{2}{|c|}{ Maior segurança no acesso e codificação de informações. } \\
\hline & \multicolumn{2}{|l|}{ Diminui o risco de obsolescência. } \\
\hline \multirow[t]{4}{*}{ 4. Prestação de serviço } & \multicolumn{2}{|c|}{ Melhoria de produtividade da Área de TI } \\
\hline & \multicolumn{2}{|c|}{ Melhora a velocidade e capacidade de resposta das atividades de TI } \\
\hline & \multicolumn{2}{|c|}{ Foca a equipe de TI interna em atividades críticas } \\
\hline & \multicolumn{2}{|l|}{ Foco em iniciativas estratégicas de TI } \\
\hline
\end{tabular}

Fonte: Elaborado pelos autores (2017) a partir de Bergamaschi (2005); Tiwana e Bush (2007); Cristofoli, Prado e Takaoka (2008); Prado (2009); Thouin, Hoffman e Ford (2009); Lopes e Silva (2008), Fitoussi e Gurbaxani (2012); Gorla e Somers (2014).

Nesse contexto, para Schawarz (2014) o sucesso em terceirização de TI é definido em razão de três aspectos: 1) Benefícios estratégicos (para a organização) - Benefícios que colaboram para que a organização contratante melhor execute estratégias e alcance objetivos 
de negócios. Requer um fornecedor hábil em compreender a ligação entre a tecnologia ofertada e os resultados desejados; 2) Benefícios tecnológicos (para a função de TI) Aquisição de novas competências técnicas e competências de gestão para melhorar o desempenho dos recursos do núcleo de TI de uma organização e; 3) Qualidade do relacionamento - Grau de qualidade percebido pelos usuários dos serviços oferecidos pelo fornecedor. A qualidade do serviço prestado pelo fornecedor deve ser significativamente maior do que a prevista pela área interna de TI.

Foina (2012), assim como Liang, Wang, Xue e Cui (2016), reforça que a terceirização de TI não deve ser encarada, apenas, como uma alternativa para redução de custos, mas também como uma estratégia para profissionalização, especialização, aumento de produtividade humana, aceleração de processos de reengenharia e resolução de conflitos internos.

Para que os benefícios anteriormente citados sejam alcançados, Perunovic e Pedersen (2007) sugerem que os processos de terceirização devem seguir as seguintes etapas:

1) Preparação - Abrange desde a decisão por terceirizar, definição dos serviços e processos a serem terceirizados; identificação de potenciais fornecedores, e decisão acerca do início do serviço;

2) Seleção - Escolha do prestador de serviço, negociação e elaboração do contrato.

3) Transição - Operacionalização do acordo e execução da troca de conhecimentos e recursos, assim como a transferência de bens, pessoas, informações, hardware, software e gerenciamento dos recursos humanos;

4) Gerência de relacionamento - Abrange a programação e coordenação de encontros e comunicações, avaliação do desempenho, solução de problemas, aplicação de incentivos e punições;

5) Reconsideração - Decisão acerca da continuidade do contrato, troca de fornecedor, e avaliação de demais mudanças.

Mann (2015) reforça que embora a terceirização de TI possa parecer uma simples escolha de negócios, a sua aplicação para qualquer empresa é complexa e requer medidas cruciais, tais como a responsável identificação das atividades que podem ser terceirizadas, adequada e cuidadosa seleção de fornecedores e realização de detalhados estudos sobre o custo-benefício do processo. 
Além disso, Prado (2009) esclarece que antes de terceirizar atividades de TI as organizações devem, cuidadosamente, identificar e avaliar suas razões e necessidades, bem como os custos do processo. Ademais, as organizações devem selecionar cuidadosa e especificamente as atividades que pretendem terceirizar ao invés de, simplesmente, terceirizar todas as atividades (Gorla \& Somers, 2014), uma vez que existe uma série de riscos e dificuldades nos relacionamentos de terceirização, os quais serão tratados no tópico a seguir.

\subsection{Principais riscos e dificuldades em relacionamentos de terceirização}

Os relacionamentos de terceirização de TI conduzem a vários benefícios resumidos, principalmente, em termos de redução de custos e melhoria de desempenho, contudo esses relacionamentos devem, também, ser encarados como atividades que implicam em riscos a performance e imagem da organização (Ensullin, 2015). Para Vieira et al (2008), assim como Giovanela e Haerthel (2008), os principais fatores de risco e desvantagens identificados ao se optar pela terceirização são: falta de capacitação/qualificação do fornecedor; perda de controle sobre a qualidade; resistência interna do pessoal técnico; perda do controle sobre os custos; resistência interna dos usuários; perda de controle sobre os prazos; cultura do terceiro não se adaptar ao padrão da empresa; falta de idoneidade do contratado; metas mal planejadas; desconhecimento da legislação trabalhista; custo de demissões; e vazamento de informações confidenciais.

Além disso, Lopes e Silva (2008) retratam que os riscos da terceirização surgem da insatisfação de algumas das partes, geralmente da empresa contratante. Os autores citam cinco causas para tal insatisfação: expectativas não atendidas do cliente em razão de promessas não cumpridas pelo fornecedor; intenções divergentes entre o cliente e o fornecedor quando o cliente busca redução de custos e o fornecedor maior receita; relutância do contratante em aceitar as mudanças propostas pelo fornecedor; estilos divergentes de gestão entre contratante e contratado e; alta rotatividade dos funcionários na empresa contratada. Os mesmos autores ainda destacam que o inadequado gerenciamento de serviços terceirizados pode resultar na falta de comprometimento, motivação, comunicação, e confidencialidade nos funcionários nativos; e consequente dificuldade para retenção e aperfeiçoamento de habilidades técnicohumanas.

Santana e Bergamaschi (2012) alertam que para minimizar riscos de terceirização, as organizações devem ser bastante criteriosas ao contratarem um terceirizado para assumir os 
serviços de tecnologia, mais que isso, as organizações contratantes devem alinhar expectativas internas e expectativas do fornecedor, preferencialmente formalizando o acordado em um documento que descreva as obrigações, padrões de qualidade e atendimento esperado. Luciano, Testa, Pilatti e Rech (2010) complementam que ao terceirizar operações de TI, as organizações necessitam ter eficientes mecanismos de controle, uma vez que a empresa terceirizada estará atuando diretamente em um dos seus ativos mais importantes, que é a sua informação.

Já para Sanchez e Martins (2013), o insucesso dos relacionamentos de terceirização é, na maioria das vezes, de responsabilidade do cliente que não se propõe a uma análise mais criteriosa quantos aos procedimentos e planejamento do processo. Esses autores afirmam que a maioria das falhas em terceirização é decorrente de: terceirizar atividades estratégicas; critérios inadequados para escolha do fornecedor; desconsiderar aspectos pessoais da personalidade dos gestores envolvidos; indefinição dos mecanismos para controle do serviço contratado; desconsiderar custos indiretos; contratos inadequados e principalmente a não definição de um plano para saída emergencial do relacionamento terceirizado.

Depois de uma ampla revisão conceitual Prado (2011) resume os fatores de riscos em terceirização de TI em função de três elementos: Cliente, transação e fornecedor. No que se refere aos clientes o risco se caracteriza pela falta de experiência e conhecimento na atividade terceirizada e no gerenciamento de contratos. Quanto às transações o autor ressalta que ambos envolvidos (cliente e fornecedor) podem não ter clareza quanto a especificidade do ativo terceirizado, incertezas quanto ao serviço a ser processado, indefinição de critérios para mensuração de resultados, interdependência entre as empresas envolvidas e proximidade com as competências essenciais da organização cliente. No tocante aos fornecedores a preocupação maior é a adoção de práticas oportunistas, assim como a falta de experiência para gerenciamento de contratos. Tais achados, principalmente, os relacionados a adoção de práticas oportunistas e gerenciamento de contratos vão ao encontro dos postulados na teoria da agência, tal como serão evidenciados a seguir.

\section{Modelo teórico para contratação e gerenciamento de serviços terceirizados de tecnologia da informação}

Os estudos em teoria da agência tratam dos sistemas de compensação de executivos e sobre o papel central do contrato, seu detalhamento e completude em relacionamentos organizacionais (Gomes, 2014). Frente ao exposto, Liang et al., (2016) completam que os 
contratos representam o mecanismo formal que legalmente conecta clientes e fornecedores na relação de terceirização de tecnologia da informação. Susarla e Barua (2011), por sua vez, defendem que na teoria da agencia a escolha acertada do tipo de contrato frente ao relacionamento das organizações e das contingências do projeto de terceirização é um indicador do sucesso do projeto. Fitoussi e Gurbaxani (2012) acrescentam que o sucesso de terceirização de serviços de tecnologia da informação será maximizado pela confecção de contratos que detalhem benefícios econômicos e recompensas tanto ao contratante (principal) quanto ao contratado (agente).

Assim, conforme apresentado, percebe-se que a elaboração e o gerenciamento de contratos são os principais elos entre teoria da agência e terceirização. Nesse sentido, a Figura 1, idealizada considerando algumas das etapas do processo de terceirização propostas por Perunovic e Pedersen (2007), expressa um modelo de possível articulação entre a teoria da agência e a terceirização de TI. A criação do modelo tem a intenção de situar as etapas do processo de terceirização, os problemas de agência e as possíveis soluções para tais problemas. 
Teoria da agência e terceirização: uma proposta de modelo teórico para contratação e gerenciamento de serviços de tecnologia da informação

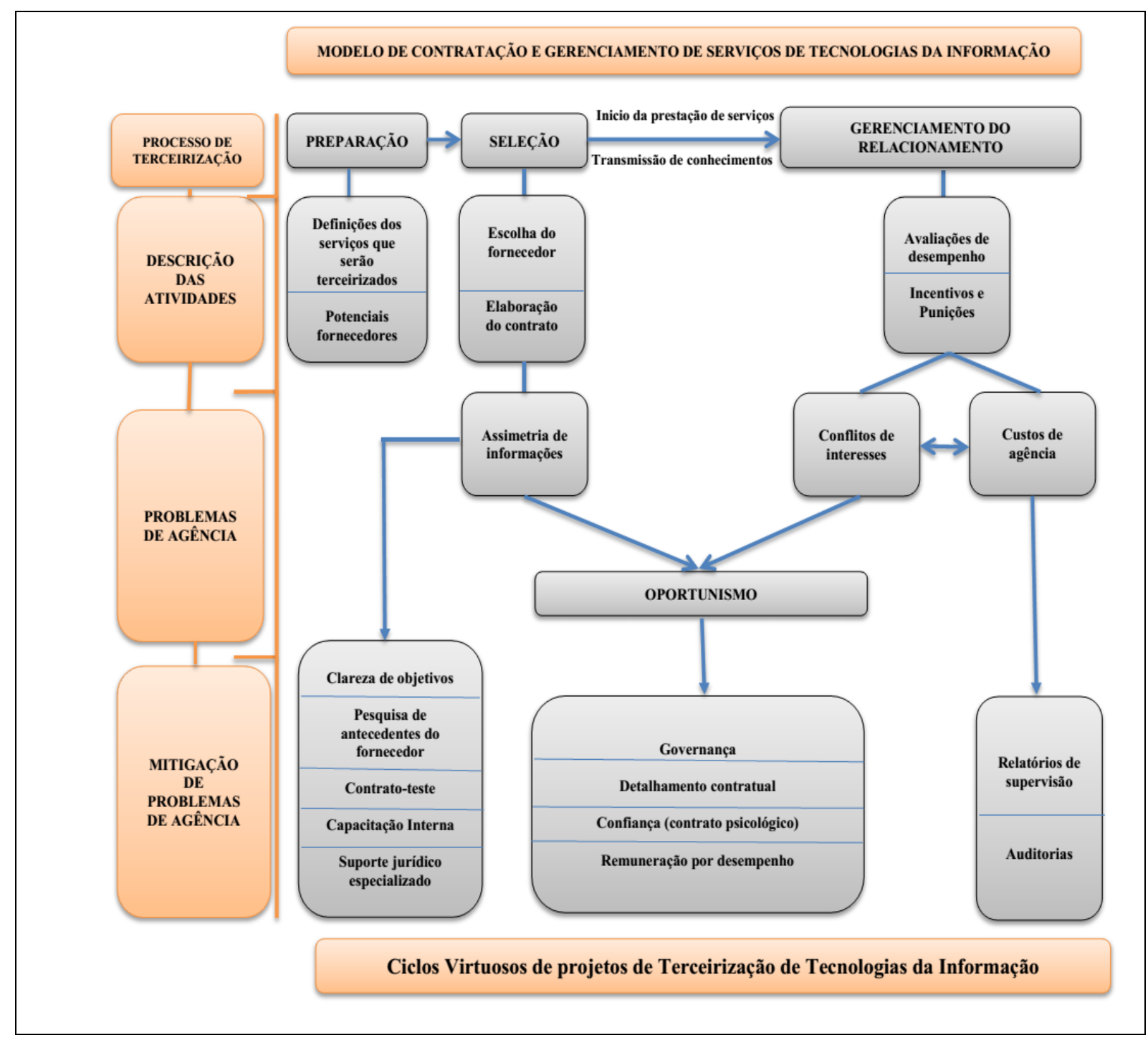

Figura 1: Modelo de contratação e gerenciamento de serviços terceirizados de TI

Fonte: Elaborado pelos autores (2017) a partir das proposições de Perunovic e Pedersen (2007)

Fitoussi e Gurbaxani (2012) acentuam que o sucesso ou insucesso em relacionamentos de terceirização é diretamente afetado pelos conflitos de interesses, expressos pelas divergências de objetivos entre as partes envolvidas. Nesse sentido, os autores reforçam que mais que descrever as atividades envolvidas, os contratos de terceirização devem ser adaptados aos objetivos pretendidos por ambos envolvidos. Nos casos em que o objetivo comum às partes envolvidas é o ganho financeiro, expresso pelo desejo de redução de custos pelo contratante e aumento de receitas pelo contratado, o contrato de terceirização deve contemplar clausulas que envolvam métricas associadas aos custos de TI, isto é, o fornecedor deverá desenvolver mecanismos que efetivamente garantam redução de custos ao cliente e este deverá proporcionar ao contratado as condições físicas e de confiança (informação e 
comunicação) para que os resultados sejam alcançados, logo, tanto contratante, como contratado, serão recompensados por seu desempenho no relacionamento terceirizado. É, também, demasiado importante que os objetivos estejam claramente definidos (clareza de objetivos) e sejam de factível alcance pelas partes envolvidas, objetivos mal caracterizados, com resultados abstratos e dificilmente mensuráveis como aumento de qualidade e maior impacto estratégico da TI devem ser evitados.

Ademais, conforme entendimento de Kim et al., (2013) contratos bem escritos em termos de benefícios, metas, responsabilidades e processos (detalhamento contratual) reduzem os efeitos de conflitos de interesses e tornam mais eficaz o relacionamento terceirizado. Os contratos de terceirização de TI devem transmitir uma clara compreensão do valor gerado pela troca de serviços empreendida, assim como especificar possíveis riscos e resultados esperados. Para Zu e Kaynark (2012) os problemas de agência podem ser superados pelo uso de mecanismos de gestão baseados em resultados, uma vez que tanto agentes quantos principais serão premiados pelo bom desempenho (remuneração por desempenho) e o conflito de interesse se tornará secundário.

Tiwana e Bush (2007) destacam que o conceito de assimetria informacional é central para modelos agente-principal em relacionamentos de terceirização, uma vez que o agente (fornecedor) tem a vantagem de possuir informações privilegiadas sobre o serviço negociado. Gorla e Somers (2014) evidenciam que existem dois tipos de riscos associados à assimetria de informações em relacionamentos de terceirização de tecnologia da informação: o risco de précontrato, aquele em que o cliente pode escolher um fornecedor inadequado por não conhecer suas reais intenções e pretensões com o relacionamento, e o risco de pós-contrato (risco moral), aquele em que o cliente não consegue identificar os níveis de esforços do fornecedor para alcance dos objetivos contratuais, isto é, o contratado pode agir de maneiras que não são diretamente observáveis pela organização cliente. Para minorar os efeitos da assimetria de informações, na etapa pré-contratual, sugere-se que a organização contratante faça uma pesquisa do histórico de contratos e rompimentos de acordos da empresa contratada, assim como obtenha informações junto a antigos e atuais clientes do possível fornecedor, de modo que seja possível identificar pontos negativos da trajetória profissional da empresa a ser contratada (pesquisa de antecedentes do fornecedor). Além disso, a organização cliente poderá, antes da lavratura de um contrato definitivo, confeccionar um "contrato-teste", pelo qual poderá, em um curto período de tempo, verificar o comportamento e potencialidades da 
empresa contratada. Evidencia-se que, muito embora, um contrato teste represente um desembolso adicional ao cliente este poderá evitar a contratação de fornecedores incapazes e de maiores prejuízos no futuro.

Ademais, é recomendável que a organização cliente capacite e especialize algum funcionário nativo nas atividades terceirizadas de TI (capacitação interna), pois dessa forma será mais fácil avaliar o desempenho da contratada e a empresa principal não se tornará "refém técnica" de seu fornecedor.

Outro ponto abordado em teoria da agência e também pertinente aos relacionamentos de terceirização são os comportamentos oportunistas, geralmente resultantes dos conflitos de interesses e assimetria de informações. O comportamento oportunista é definido como a falta de confiança de que o fornecedor e/ou cliente vai honestamente cumprir as obrigações do projeto de terceirização. Nesse contexto, Tiwana e Bush (2007) defendem que a organização contratante deve implementar mecanismos complexos, e até mesmo, dispendiosos de governança para salvaguardar os seus interesses em suas operações com um fornecedor. Qui e Chau (2012) complementam que o alto nível de detalhes e especificidades contratuais, regidos por normais legais, dificultam o envolvimento em práticas oportunistas. Prado (2011) ainda destaca que as práticas oportunistas devem ser mitigadas pela construção de um relacionamento juridicamente consistente e pautado em confiança de modo que nem clientes, nem fornecedores busquem obter vantagens em detrimento do parceiro, mesmo que tenham oportunidade para isso.

Além disso, para obstar práticas oportunistas em relacionamentos de terceirização de TI, mais que estruturar contratos repletos com regras, é preciso construir relacionamentos pessoais e organizacionais pautados em flexibilidade, confiança, comprometimento e interdependência. Um relacionamento terceirizado bem sucedido é baseado em um contrato formal enraizado por laços de confiança que fortalecem o vínculo entre clientes e prestadores de serviços (Lee \& Choi, 2011). Inclusive, a confiança interpessoal, que funciona como um contrato psicológico, tem um efeito mais forte que a confiança interorganizacional para impedir o surgimento de comportamentos oportunistas, garantir aprendizagem cooperativa na transferência de conhecimentos e alavancar o sucesso do relacionamento de terceirização (Ndubisi, 2011; Liang et al., 2016).

Percebe-se que à medida que os conflitos de interesses e a assimetria de informações são minimizados, os comportamentos oportunistas perdem força em relacionamentos de 
terceirização de TI, e consequentemente os custos de agência tendem a ser menores. Cabe destacar, no entanto, que os custos de agência (monitoramento) não devem ser vistos apenas como dispêndios financeiros para que o agente cumpra com as determinações do principal, mas sim como investimentos - tais como elaboração de relatórios de supervisão, realização de auditorias interna e contratação de auditorias externas - que garantem a maior eficácia e segurança dos serviços prestados por terceiros. Assim, os custos de agência devem ser encarados como instrumentos que criam condições para maximização de investimentos e maiores retornos futuros.

De modo geral, e em conformidade com as percepções de Tiwana e Bush (2007), a confecção de contratos detalhados, técnica e juridicamente bem embasados, aliados a eficientes sistemas de monitoramento e supervisão, constituem a principal contribuição da teoria da agência aos relacionamentos terceirizados. É de ressaltar que, como na maioria das vezes, tanto cliente, quanto fornecedor não tem experiência na confecção de contratos jurídicos deve-se acionar serviços de advogados especializados (suporte jurídico especializado), a fim de garantir maior validade a esse instrumento (Terribili Filho, 2014).

Ademais, contratos bem concebidos tendem a melhorar o desempenho dos relacionamentos de terceirização de tecnologia da informação, incluindo a maior eficiência de investimentos e redução de custos, maior clareza informacional e alinhamento de interesses e objetivos entre as partes envolvidas (Kim et al., 2013). Em síntese o equilíbrio entre confiança, contrato formal e estruturas de controle conduz os projetos terceirizados a ciclos virtuosos, trazendo sucesso para todos os envolvidos (Prado, 2011).

\section{Conclusões}

Este artigo teve como objetivo principal analisar como os pressupostos da teoria da agência podem mitigar problemas nos processos de contratação e gerenciamento de serviços terceirizados de TI. Adotou-se que os relacionamentos de terceirização de tecnologia da informação (TI) são conduzidos por vínculos contratuais, e que a teoria da agência estuda as relações contratuais entre indivíduos e entes organizacionais, inclusive nas relações de terceirização, de modo que a complementariedade entre essas duas temáticas se mostrou relevante para propor mecanismos mitigadores para riscos que envolvem conflitos de interesses, assimetria de informações e custos de monitoramento em relacionamentos de terceirização. 
Destacou-se que as empresas costumam ingressar em relacionamentos de terceirização em busca de redução de custos e foco em atividades essenciais, contudo, percebeu-se, também, que relacionamentos de terceirização bem gerenciados são capazes de atribuir valor estratégico e melhor desempenho às entidades participantes.

Assim, como foi apresentado ao longo desse trabalho, existem algumas ações capazes de minorar os problemas causados em relacionamentos de terceirização, principalmente aqueles relacionados aos pressupostos de teoria da agência: assimetria de informações, conflitos de interesses e custos de agência.

Dentre as contribuições da teoria da agência avultou-se a orientação por modelar contratos que sejam capazes de maximizar o esforço das partes envolvidas em prol do empreendimento. Nas questões relativas aos conflitos de interesses ficou evidente que é necessário despertar nas partes envolvidas um sentimento comum de pertencimento, desenvolvimento e crescimento organizacional, além de, também, claramente demonstrar que os ganhos financeiros estão atrelados ao trabalho conjunto, baseado em fortes bases jurídicas, e alto nível de confiança interpessoal.

Quanto à assimetria de informações foi percebido que a qualificação e especialização de um indivíduo ou um grupo de funcionários em ambas as organizações participantes é uma viável alternativa às práticas oportunistas que podem surgir da assimetria informacional.

Por falar em práticas oportunistas, ficou explícito que contratos juridicamente bem embasados, alinhados a contratos psicológicos em termos de confiança interpessoal, e eficientes mecanismos de supervisão e punição são ações que podem consideravelmente diminuir a frequência de práticas oportunistas. Aqui cabe uma ressalva, a literatura, na maioria das vezes, quando trata do relacionamento entre principal e agente tende a atribuir ao agente às práticas oportunistas, nesse sentido, o comportamento oportunista, que objetiva ganhos individuais e maximização de objetivos particulares, pode se manifestar tanto em agentes, quanto em principais, o que só reitera a importância de um relacionamento de terceirização - contrato - pautado em confiança, precisão, integralidade, equilíbrio e equidade jurídica.

Quanto aos custos de monitoramento (custos de agência), a contribuição desse estudo está em propor o entendimento de tais custos como desembolsos no presente com potencial de maximização de investimentos num futuro breve e não apenas como dispêndios indesejados. 
Com base nisso, foram sugeridas ações com potencial de mitigar riscos e potencializar o sucesso de relacionamentos de terceirização. As referidas ações, conforme descritas no modelo apresentado, são destinadas a resolver problemas de agência, que são também problemas dos relacionamentos de terceirização, reforçando a contribuição do modelo para conhecimento e ampliação de ciclos virtuosos de terceirização de TI em organizações públicas e privadas.

Obviamente, a validação do modelo e a verificação de sua eficácia estão condicionadas a sua aplicação em uma situação real, logo seus resultados carecem de comprovação empírica. Nesse sentido são sugeridas novas pesquisas a fim de verificar a eficácia e validade do modelo proposto em relacionamentos de terceirização de TI, e/ou demais relacionamentos terceirizados, em empresas privadas, assim como em entidades púbicas.

\section{Referências}

Arruda, G.S., Madruga, S.R., \& Freitas Jr., N.I. (2009). A Governança Corporativa e a Teoria da Agência em Consonância com a Controladoria. Revista de Administração da UFSM, 1, 71-84, jan./abr.

Barros, J. G. B. R. (2008). O papel da terceirização na informática do INES. 2008, 63 f. Monografia (Especialista em Gestão Pública) - Universidade Cândido Mendes, Rio de Janeiro.

Bendickson, J., Muldoon, J., Liguori, E., \& Davis, P.E. (2016). Agency theory: the times, they are a-changin. Management Decision, 54 (1), 174-193, February.

Bergamaschi, S. (2005). Modelos de gestão da terceirização de tecnologia da informação: um estudo exploratório. 2005, 197 f. Tese (Doutor em Administração) Universidade de São Paulo, São Paulo.

Bitti, E. J. S. (2015). O Setor de Franchising no Brasil: Identificando Grupos Estratégicos pela Ótica da Teoria da Agência e pela Visão de Recursos Escassos. Organizações em contexto, 11 (22).

Braga, G. S., Horbucz, K. S. N., \& Cherobim, A. P. M. S. (2015). Influência do investimento anjo na tomada de decisão e nos problemas de agência: um estudo de caso. Revista de Empreendedorismo e Gestão de Pequenas Empresas, 4 (1).

Cristofoli, F., Prado, E. P. V., \& Takaoka, H. (2008). Sourcing de serviços de TI: um estudo de caso do setor automobilístico brasileiro. In: SEMEAD, 10. 2008, São Paulo. Anais... São Paulo. 
Cristofoli, F., \& Prado, E. P. V. (2011). Terceirização de Serviços de Tecnologia da Informação. Rev. Elet. Gestão e Serviços. 2 (2).

Eisenhardt, K. M (1989). Agency theory: An assessment and review. Academy of management review, 14 (1), 57-74.

Ensslin, L., Mussi, C., Chaves, L. C., \& Demetrio, S. N. (2015). It outsourcing management: the state of the art recognition by a constructivist research process and bibliometric system. Journal of Information Systems and Technology Management, 12 (2), 371-392, May/Aug.

Fitoussi, D., \& Gurbaxani, V. (2012). IT Outsourcing Contracts and Performance Measurement. Information Systems Research, Irvine, 23 (1), 129-143.

Foina, P. R. (2012). Tecnologia de informação, planejamento e gestão. 2. ed. São Paulo: Atlas.

Foina, P. R., \& Lima, P. de S (2014). Processos de gestão de terceirização em Tecnologia da Informação: estudo de caso. Universitas Gestão e TI, Brasília, 4 (2), 51-57, jul./dez.

Kearney, A. T. (2017). Global Service Location On the even of the disruption. Disponível em: $<$ https://www.atkearney.com/documents/20152/793366/The+Widening+Impact+o f+Automation.pdf/42b06cf4-e5f9-d8ec-a30c-a82dd26d4953> . Acesso em: Fev. 2018.

Giovanela, A., \& Haerthel, S. M. (2008). Terceirização: vantagens e desvantagens. Percepção dos colaboradores e gestores na empresa de tecnologia de informação (TI). Revista Interdisciplinar Científica Aplicada, 3 (4), 488-511.

Gomes, G. S. (2014). Análise de projetos terceirizados de ti sob a ótica das teorias da agência e de desenvolvimento de grupos. 2014, 138 f. Dissertação (Mestrado em administração) - Pontifícia Universidade Católica do Rio Grande do Sul, Porto Alegre.

Gonçalves, A. de P., Polo, E. F., Correa, H. L., \& Castelhano Bruno, M. A (2010).

Estratégia de terceirização de sistemas de informação e de alinhamento estratégico entre negócios e TI. Gestão \& Regionalidade, 6 (77) - mai-ago.

Gorla, N., Somers, T. M. (2014). The impact of IT outsourcing on information systems success. Information \& Management, 51(3), 320-335, April.

Heracleous, L., \& Lan, L. L. (2012). Agency Theory, Institutional Sensitivity, and Inductive Reasoning: Towards a Legal Perspective. Journal of Management Studies, 49 (1), 223-239.

Gens, F., SVP \& Chief Analyst (2017). IDC FutureScape: Worldwide IT industry 2018 Predictions. Disponível em: <https://www.brighttalk.com/webcast/15909/277209>. Acesso em: Fev. 2018.

Jensen, M. C., \& Meckling, W.H. (1976) Theory of Firm: Managerial Behavior. Agency Costs and Ownership Structure. Journal of Financial Economics, Rochester, 3, 305360, Jul. 
Jensen, Michel C., \& Meckling, W. H. (1994). Foundations of organizational strategy. Journal of Applied Corporate Finance, 7 (2), 4-19.

Kaveski, I. D. S., \& Cunha, P. R. (2016). Fatores Determinantes dos Honorários da Auditoria das Empresas Listadas no Novo Mercado da BM\&F BOVESPA. Contabilidade, Gestão e Governança, 19 (1), 49-63.

Kim, Y. J., Lee, J. M., Koo, C., \& Nam, K. (2013). The role of governance effectiveness in explaining IT outsourcing performance. International Journal of Information Management, 33 (5), 850-860.

Klann, R. C., Gomes, E. C. O., Greuel, M. A., \& Bezerra, F. A. (2014). Influência do Risco Moral e da Accountability nas tomadas de decisões. Contabilidade Vista \& Revista, 25 (1), 99-118.

Lee, J. N., \& Choi, B. (2011). Effects of initial and ongoing trust in IT outsourcing: A bilateral perspective. Information \& Management, 48, 96-105.

Liang, H., Wang, J. J., Xue, Y., \& Cui, X. (2016). IT outsourcing research from 1992 to 2013: A literature review based on main path analysis. Information \& Management, 53 (2), p.227-251.

Linder, S., \& Foss, N. J. (2015). Agency Theory. International Encyclopedia of the Social \& Behavioral Sciences, v. 1.

Lopes, A. L. S. V., \& Silva, J. R. G. (2008). Casos de terceirização e a influência sobre o contrato psicológico de profissionais de TI. Revista eletrônica de Gestão Organizacional, 6, 249-270.

Luciano, E. M., \& Testa, M. G. (2011). Controles de governança de tecnologia da informação para a terceirização de processos de negócio: uma proposta a partir do cobit. Revista de Gestão da Tecnologia e Sistemas de Informação, 8, 237-262.

Luciano, E. M., Testa, M. G., Pilatti, L., \& Rech, I. (2010) Aplicabilidade do COBIT na gestão de atividades de tecnologia da informação terceirizadas: uma investigação com base em duas empresas multinacionais. Revista Eletrônica de Sistemas de Informação, v. 9.

Machado, D. Q., Garcia, E. A. R., Oliveira, M. C., \& Marques, E. C. O. (2015). O Caso Barings: as Lições foram Aprendidas?. Revista Alcance, 22 (2), 316-329.

Mann, A., Folch, D. C., Kauffman, R. J., \& Anselin, L. (2015). Spatial and temporal trends in information technology outsourcing. Applied Geography, 63, 192-203, September.

Meneghetti, F. K. O que é um Ensaio-Teórico? Revista de Administração Contemporânea, 15 (2), 320-332, mar./abr. 
Mercado Brasileiro de Software: Panorama E Tendências- $1^{\mathrm{a}}$. ed. - São Paulo: ABES Associação Brasileira das Empresas de Software, 2016.

Mitchell, R., \& Meacheam, D. (2011). Knowledgment worker control: understanding via principal and agency theory. The Learning Organization, Newcastle, 149-160. jun.

Mol, M. J. (2007). Outsourcing: design, process and performance. United Kingdom: Cambridge UniversityExpress.

Moraes, C. Z. (2015). Governança Corporativa: Uma Visão Sob a Teoria da Agência. Revista de ciências gerenciais, 19 (30), 34-40.

Moura, F. V., Daniel, A. F., Gomes, J. N., Pereira, J. J. (2014). Conflitos de Agência, Legitimidade e o discurso sobre Governança Corporativa: o caso Petrobras. In: XI Congresso USP Iniciação cientifica contabilidade, 2014, São Paulo: USP, 2014.

Ndubisi, N. O. (2011). Conflict handling, trust and commitment in outsourcing relationship: A Chinese and Indian study. Industrial Marketing Management, 40 (1), 109-117.

Perunovic, Z., \& Pedersen, J. (2007). Outsourcing Process and Theories. In: annual conference of the production and operation management SOCIETY, 18. Proceedings. Dallas: 2007. Disponível em: https://www.pomsmeetings.org/confpapers/007/0070003.pdf. Acesso em 22 jun. 2016.

Prado, E. P. V. (2009). Terceirização de serviço de TIC: uma avaliação sob o ponto de Vista do fornecedor. REAd Revista Eletrônica de Administração, 15.

Qi, C., \& Chau, P. Y.K. (2012). Relationship, contract and IT outsourcing success: Evidence from two descriptive case studies. Decision Support Systems, 53(4), 859869.

Rocha, I., Pereira, A. M., Bezerra, F. A., \& Nascimento, S. (2012). Análise da produção científica sobre teoria da agência e assimetria da informação. REGE São Paulo - SP, Brasil, 19 (2), 327-340.

Rodrigues, A. A. D. O. N. (2013). Uma análise comparativa entre a Teoria da Agência e a Stewardship. Revista Fafibe Online, 6, 67-77.

Saito,R., \& Silveira, A. M. (2008). Governança corporativa: custos de agência e estrutura de propriedade. Revista de administração de empresas, 48, 79-86.

Samantra, C., Datta, S., \& Mahapatra, S. S. (2014). Risk assessment in IT outsourcing using fuzzy decision-making approach: An Indian perspective. Expert Systems With Applications, 41 (8), 4010-4022.

Sanchez, O., Martins, Á. L. M. (2013). Percepção de valor nos anúncios de terceirização de infraestrutura de TI: Um estudo de eventos com empresas brasileiras. Revista de Administração e Contabilidade da Unisinos, 10, 154-168. 
Santana, V. A. S., \& Bergamaschi, M. P. (2012). Outsourcing de TI: Motivos e riscos de terceirizar serviços de TI. Revista Ceciliana, 33, 124-133.

Santos, M. M., Inácio, H. C., \& Vieira, E. S. (2015). Governo das Sociedades e a Opinião do Auditor: Evidência Portuguesa (2008-2011). Revista Universo Contábil, 11 (3), 150-168.

Schwarz, C. (2014). Toward an understanding of the nature and conceptualization of outsourcing success. Information \& Management, 51, 152-164.

Susarla, A., \& Barua, A. (2011). Contracting efficiency and new firm survival in markets enabled by information technology. Information Systems Research, 22 (92), 306-324.

Terribili Filho, A. (2014). Outsourcing: histórico, benefícios, riscos e abordagem metodológica de Greaver II. Disponível em: <http://www.impariamo.com.br/base-deconhecimento/artigos/tecnologia-da-informacao/item/194-outsourcing-historicoconceitos-beneficios-riscos-e-a-abordagem-metodologica-de-greaver-ii >. Acesso em: 21 jun. 2016.

Thouin, Mark F., Hoffman, J. J., \& Ford, E. W. (2009). IT outsourcing and firm-level performance: A transaction cost perspective. Information \& Management, 46 (8), 463469.

Tiwana, A., \& Bush, A. A. (2007). A comparison of transaction cost, agency, and knowledge-based predictors of IT outsourcing decisions: A US-Japan cross-cultural field study. Journal of Management Information Systems, 24 (1), 259-300.

Vieira, C. H. G., Diogenes, M. C. C., Santos, V. S., Oliveira, E. A. A. Q., \& Quintairos, P. C. R. (2008). Terceirização do setor de ti: quais serviços terceirizar e porquê. In: XII Encontro Latino Americano de Iniciação Científica e VIII Encontro Latino Americano de Pós-Graduação, 2008, São Paulo: Universidade do Vale do Paraíba. Disponível em: <http://www.inicepg.univap.br/cd/INIC_2008/anais/arquivosEPG/EPG00194_02_O.p df>. Acesso em: 21 jun. 2016.

Zu, X., \& Kaynak, H. (2012). An agency theory perspective on supply chain quality management. International Journal of Operations \& Production Management, 32, 423-446. 